\title{
A decision tree model to estimate the value of information provided by a groundwater quality monitoring network
}

\author{
A. I. Khader ${ }^{1, *}$, D. E. Rosenberg ${ }^{1}$, and M. McKee ${ }^{1}$ \\ ${ }^{1}$ Utah State University, Logan, UT, USA \\ * currently at: McMaster University, Hamilton, ON, Canada
}

Correspondence to: A. I. Khader (abdelhaleem.khader@aggiemail.usu.edu)

Received: 22 November 2012 - Published in Hydrol. Earth Syst. Sci. Discuss.: 18 December 2012

Revised: 7 March 2013 - Accepted: 15 April 2013 - Published: 8 May 2013

\begin{abstract}
Groundwater contaminated with nitrate poses a serious health risk to infants when this contaminated water is used for culinary purposes. To avoid this health risk, people need to know whether their culinary water is contaminated or not. Therefore, there is a need to design an effective groundwater monitoring network, acquire information on groundwater conditions, and use acquired information to inform management options. These actions require time, money, and effort. This paper presents a method to estimate the value of information (VOI) provided by a groundwater quality monitoring network located in an aquifer whose water poses a spatially heterogeneous and uncertain health risk. A decision tree model describes the structure of the decision alternatives facing the decision-maker and the expected outcomes from these alternatives. The alternatives include (i) ignore the health risk of nitrate-contaminated water, (ii) switch to alternative water sources such as bottled water, or (iii) implement a previously designed groundwater quality monitoring network that takes into account uncertainties in aquifer properties, contaminant transport processes, and climate (Khader, 2012). The VOI is estimated as the difference between the expected costs of implementing the monitoring network and the lowest-cost uninformed alternative. We illustrate the method for the Eocene Aquifer, West Bank, Palestine, where methemoglobinemia (blue baby syndrome) is the main health problem associated with the principal contaminant nitrate. The expected cost of each alternative is estimated as the weighted sum of the costs and probabilities (likelihoods) associated with the uncertain outcomes resulting from the alternative. Uncertain outcomes include actual nitrate concentrations in the aquifer, concentrations reported by the monitoring system, whether people abide by manager recommendations to
\end{abstract}

use/not use aquifer water, and whether people get sick from drinking contaminated water. Outcome costs include healthcare for methemoglobinemia, purchase of bottled water, and installation and maintenance of the groundwater monitoring system. At current methemoglobinemia and bottled water costs of $\$ 150 /$ person and $\$ 0.6 /$ baby/day, the decision tree results show that the expected cost of establishing the proposed groundwater quality monitoring network exceeds the expected costs of the uninformed alternatives and there is no value to the information the monitoring system provides. However, the monitoring system will be preferred to ignoring the health risk or using alternative sources if the methemoglobinemia cost rises to $\$ 300$ /person or the bottled water cost increases to $\$ 2.3 /$ baby/day. Similarly, the monitoring system has value if the system can more accurately report actual aquifer concentrations and the public more fully abides by manager recommendations to use/not use the aquifer. The system also has value if it will serve a larger population or if its installation costs can be reduced, for example using a smaller number of monitoring wells. The VOI analysis shows how monitoring system design, accuracy, installation and operating costs, public awareness of health risks, costs of alternatives, and demographics together affect the value of implementing a system to monitor groundwater quality.

\section{Introduction}

In many places throughout the world, groundwater is the sole drinking water source but is contaminated by nitrate $\left(\mathrm{NO}_{3}^{-}\right)$ and other constituents generated from human activities such as agriculture, industry, municipal waste, septic tanks, 
cesspits, and dairy lagoons (Almasri and Kaluarachchi, 2005). When ingested, nitrate decreases the ability of human blood to carry oxygen, which can result in oxygen deficiency and cause methemoglobinemia (blue baby syndrome) and other health problems including dizziness, headache, loss of muscular strength, hemolysis, seizures, or in the most extreme cases, death (Majumdar, 2003). Infants are more susceptible than adults (Lorna, 2004), with susceptibility depending on the $\mathrm{NO}_{3}^{-}$concentration in contaminated water (Walton, 1951). For example, infants who drink water with $\mathrm{NO}_{3}^{-}$concentrations less than $45 \mathrm{mg} \mathrm{L}^{-1}$ are unlikely to get the disease. On the other hand, $57 \%$ of infants who drink water with $\mathrm{NO}_{3}^{-}$concentrations between 45 and $225 \mathrm{mg} \mathrm{L}^{-1}$ will experience methemoglobinemia, and almost all infants who drink water with $\mathrm{NO}_{3}^{-}$concentrations greater than $225 \mathrm{mg} \mathrm{L}^{-1}$ will be affected. These health risks create a need to intensively monitor and manage groundwater resources that might be susceptible to nitrate contamination.

Effective groundwater monitoring and management must provide reliable information about groundwater quality, the likelihood of different groundwater quality outcomes, and the costs and consequences of potential outcomes and actions. However, information is not free; it requires money and time to acquire (Sakalaki and Kazi, 2007). Thus when deciding whether to ignore a contamination problem, use alternative sources of water, or design and implement a groundwater quality monitoring network, it is important to consider the value of information (VOI) provided by the monitoring network. The VOI compares the present-value, the expected net benefits of collecting additional information to reduce or eliminate uncertainty associated with the outcomes of a decision to the present-value, and the expected net benefits of a preferred uninformed alternative (Alfonso and Price, 2012; Chia-Yu Lin et al., 1999; Dakins, 1999; Dakins et al., 1994, 1996; Delquié, 2008; Rajagopal, 1986; Repo, 1989; Sakalaki and Kazi, 2007; Yokota and Thompson, 2004a,b). VOI makes explicit any expected losses from errors in decision-making due to uncertainty and identifies the preferred information collection strategy as the one that leads to the greatest expected net benefit to the decision-maker (Yokota and Thompson, 2004a).

To estimate net benefits, managers and decision-makers (DMs) can use expected utility (EU) theory (Delquié, 2008). In economics, utility is a set of numerical values that reflect consumer satisfaction from receiving a good or service, such as clean drinking water. EU is calculated by weighting the utility of each potential outcome (such as polluted or clean drinking water) by the outcome probability (Perloff, 2008). For public policy decisions where consequences are small compared to the scale of the overall enterprise, we can substitute expected value (EV; measured in value units such as dollars) for EU (Arrow and Lind, 1970). Like EU, the EV of each decision is calculated by weighting the value of each potential outcome by the outcome probability.
A decision tree model describes the logical structure of the decisions, uncertainties, and potential outcomes (Fig. 1), and can help estimate EU or EV (Lund, 2009). In the figure, boxes denote choice nodes where decisions are made. Circles denote chance nodes where information is revealed. Each branch emanating from a choice node represents an alternative, and each branch emanating from a chance node represents an uncertain outcome with a specified probability. Each outcome consequence is shown on a terminal branch at the far right of the tree. In Fig. 1, the DM has two uninformed alternatives (branches 1 or 2) or may acquire more information about the system to later make a more informed decision (branch 3).

The VOI is measured ex ante (i.e., based on expected utility or value) as the difference between the EUs or EVs of the informed and uninformed branches (Delquié, 2008; LaValle, 1968). When the $\mathrm{EV}$ of the informed alternative is larger than the EV of the uninformed alternative, VOI is positive and there will be a benefit to acquire more information.

Willingness to pay (WTP) is another widely used method to estimate VOI (Alberini et al., 2006; Bouma et al., 2009; DeShazo and Cameron, 2005; Dickie and Gerking, 2002; Engle-Warnick et al., 2009; Latvala and Jukka, 2004; Molin and Timmermans, 2006; Roe and Antonovitz, 1985; Sakalaki and Kazi, 2007) and is defined as the maximum amount a person or a DM is willing to pay to receive a good or to avoid something undesirable (Perloff, 2008). Researchers survey individuals and ask them to state how much they are willing to pay for additional information (Alberini et al., 2006; Atkins et al., 2007; Pattanayak et al., 2003). Alternatively, researchers can embed the WTP questions in valuation experiments where participants express their WTP for certain outcomes and then receive rewards/penalties based on their responses and subsequent chance outcomes (Friedman and Sunder, 1994). Both WTP methods require a large number of participants, repeat the method multiple times with individual participants, measure WTP ex post from the responses, and assume that participants understand the meanings, outcomes, and likelihoods of the situation posed and are vested in the outcome. For situations where there are only a small number of decision-makers, such as a groundwater monitoring system design, the EU method can estimate how rational people should value information and provides an upper bound for WTP that is sufficient for VOI analysis.

This paper uses a decision tree model to estimate the value of information provided by a proposed nitrate groundwater quality monitoring network for the Eocene Aquifer, West Bank, Palestine. The proposed monitoring network and placement of observation wells consider uncertainties in aquifer properties, contaminant transport processes, and climate (Khader, 2012). At present, Eocene Aquifer managers must decide whether to (i) ignore the nitrate contamination problem (and face the risk of methemoglobinemia); (ii) recommend households switch to alternative culinary water sources such as bottled water; or (iii) implement the proposed 


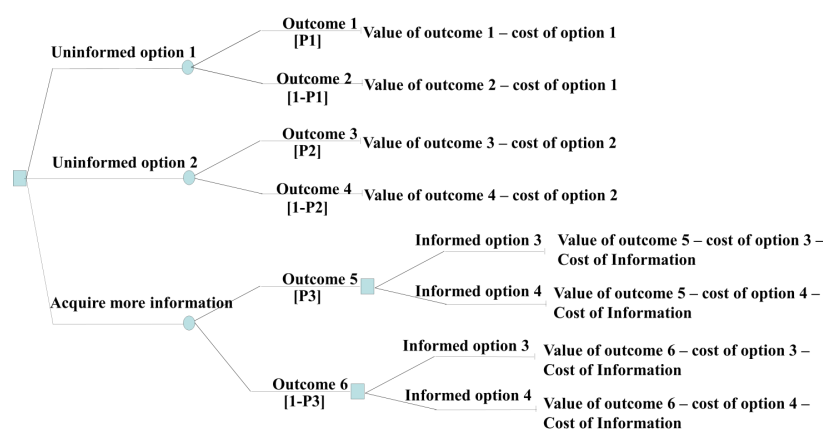

Fig. 1. Example decision tree with three alternatives yielding six potential outcomes with probabilities $\mathrm{P} 1, \mathrm{P} 2, \mathrm{P} 3$, and complements 1-P1, 1-P2, and 1-P3.

groundwater quality monitoring system and then use monitoring results to recommend whether households should either continue to use the aquifer for culinary purposes or switch to alternative water sources. These options differ in their implementation costs, outcomes, likelihood that babies will get sick with methemoglobinemia, and associated consequences. These costs, outcomes, and likelihoods are further affected by whether the public will abide by manager recommendations to use or not use water from the aquifer for inhome consumption. These costs and uncertainties challenge the decision-maker and identify the need for a decision tool that can identify the expected values of the options, determine the value of information provided by the monitoring system, and help DMs choose a preferred alternative.

Past VOI research in fields like general environmental health, water contamination, and toxicology applications has focused on demonstrating the usefulness of the VOI approach (Yokota and Thompson, 2004b). Here, our main contribution is to use the decision tree framework to estimate the value of implementing a groundwater quality monitoring network. Other contributions include applying the approach to help inform aquifer monitoring and management decisions, and showing how the VOI is influenced by a multitude of design, public awareness, financial, demographic, and demographic-hydrogeological factors, such as monitoring system design and accuracy, public abidance with manager recommendations, costs of alternatives, size of the population, and location of the population in relation to areas that pose a health risk.

The next section briefly describes the study area and proposed monitoring network. Sections 3 and 4 present the decision tree components and results from the VOI calculations and sensitivity analyses. Section 5 concludes.

\section{Study area and proposed monitoring network}

The methodology of this research is demonstrated using the Eocene Aquifer, which is an unconfined aquifer located in the northern part of the West Bank, Palestine (Fig. 2). Nitrate is the main contaminant in the Eocene Aquifer. The main reasons for nitrate contamination in the aquifer are the excessive use of nitrogen-rich fertilizers and the lack of sewer networks (Najem, 2008). Nitrate contamination may cause methemoglobinemia for people who live in the area and use the aquifer for culinary purposes.

The Eocene Aquifer is used to meet domestic and agricultural demands for more than 207000 Palestinians living in 66 communities, including 53000 people in the City of Jenin (PCBS, 2009). Annual population growth in the area is $3.0 \%$ and the average household size is 5.5 (PCBS, 2008).

In prior work, Khader (2012) used a groundwater flow model, nitrate fate and transport model, and 10000 Monte Carlo (MC) simulations to capture the effects of uncertainties in aquifer recharge, hydraulic conductivity, and nitrate reaction processes on nitrate concentrations throughout the Eocene Aquifer. The results were estimates of the spatial distribution of nitrate concentrations across 519 active $1000 \mathrm{~m}$ by $1000 \mathrm{~m}$ aquifer model cells in a finite difference grid that represents the aquifer (Fig. 2, right); within each cell there is also a probability distribution of nitrate concentration.

Khader (2012) also used uncertainties revealed through the Monte Carlo simulations to design a groundwater nitrate monitoring network for the Eocene Aquifer. The design shows the proposed locations of 49 monitoring wells and takes into account uncertainties in climate, aquifer properties, and expected nitrate concentrations. To design the network, Khader (2012) used a relevance vector machine (RVM) to build a best-fit model of nitrate concentration distribution everywhere in the aquifer for each Monte Carlo subset. The Monte Carlo simulations yield 10000 nitrate concentration values for each aquifer water model cell. However, available RVM modeling tools cannot handle a problem of this size, so Khader (2012) performed 100 RVM model runs where in each run, 100 nitrate concentration targets for each cell were randomly but conditionally sampled from the total Monte Carlo population to preserve the spatial correlation of concentrations between cells. The RVM model outputs include the spatial distribution of nitrate concentration everywhere in the aquifer, the uncertainty in the characterization of those concentrations, and the number and locations of "relevance vectors" (RVs). The RVs form the basis of the optimal characterization of nitrate throughout the aquifer and can be used to determine the optimal locations of monitoring wells, predict nitrate concentrations throughout the aquifer, and characterize the uncertainties associated with those predictions. Here, we use all these outputs to calculate the value of information associated with the monitoring network.

\section{Decision tree analysis}

The decision tree depicts the structure of the problem of how to respond to uncertain outcomes like potential aquifer 


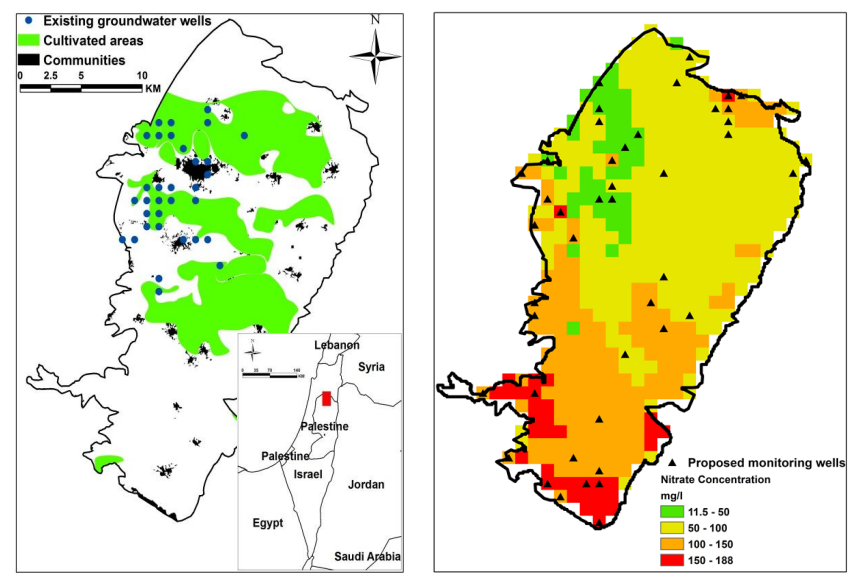

Fig. 2. Eocene Aquifer study area. (Left) Palestinian communities, abstraction wells, and cultivated areas. (Right) Average nitrate concentrations predicted by Monte Carlo simulations and proposed monitoring well locations (Khader, 2012).

contamination. We consider three alternatives: (i) do nothing (ignore the nitrate contamination problem), (ii) switch to alternative sources of water, or (iii) implement a groundwater quality monitoring network that reduces uncertainty about groundwater quality and informs subsequent manager recommendations such as to continue to use the aquifer or switch to alternative sources (Fig. 3). The decision tree can also be used to calculate the value of information associated with the alternative to monitor to reduce uncertainty.

Ignoring the problem and not testing for nitrate contamination is one uninformed option in which the DM will encourage people to use the aquifer for culinary purposes and face a health risk if the aquifer water is contaminated (nitrate concentration greater than $45 \mathrm{mg} \mathrm{L}^{-1}$ ). If the water in an aquifer model cell is contaminated and people who use that water get sick, there will be a cost associated with methemoglobinemia treatment in the form of methylene blue. Methylene blue converts methemoglobin ( $\mathrm{MHb}$ ) to hemoglobin, gives immediate relief (Majumdar, 2003), but costs about $\$ 150$ per case (http://www.revolutionhealth. com/drugs-treatments/methylene-blue), which is considered a high cost by the people living in the West Bank. This cost will be considered as a one-time cost and it will be further analyzed in the sensitivity analysis in Sect. 4. As a second uninformed alternative, the DM can immediately recommend that people not use water from the aquifer to prepare baby formula and instead switch to alternative sources, such as bottled water. In this case, the supply costs are higher; however, everyone will stay healthy. As a third option, the DM can acquire more information about the groundwater quality and the spatial distribution of nitrate concentration. There will be capital costs to design the monitoring network and drill and finish monitoring wells, as well as on-going costs to regularly collect and analyze groundwater samples and operate and maintain the wells. The DM can use monitoring results to estimate groundwater quality throughout the aquifer and then, based on the monitoring results, recommend whether people should (i) continue to use the aquifer, or (ii) switch to alternative sources. However, monitoring and estimation of nitrate concentrations are imperfect, so when people continue to use the aquifer there is still a possibility that estimated concentration in their water will differ from the actual concentration. For example, if the monitored/estimated concentration is less than $45 \mathrm{mg} \mathrm{L}^{-1}$, the actual concentration might be larger than $45 \mathrm{mg} \mathrm{L}^{-1}$. In this situation, people still face a health risk: they could get sick and require methemoglobinemia treatment even though they followed the DM's recommendation to continue to use water from the aquifer. Thus, with monitoring, there are also additional recourse costs that depend on the monitoring results and whether managers subsequently advise households to continue to use the aquifer or use alternative sources. Figure 3 shows this decision tree structure for the case when people fully abide by DM recommendations.

The decision tree structure changes for a second case where only some people abide by DM recommendations (Fig. 4). In this case, there are additional branches from each node where a DM recommends what people should do; these branches represent people who (i) abide by and (ii) ignore DM recommendations. Probabilities A1, A2, A3, A4, 1-A1, 1-A2, 1-A3, and 1-A4 define the likelihoods that people will abide by and ignore the recommendations and are not found in Fig. 3 (for the case of full abidance). The additional outcomes represent public awareness and acceptance of DM recommendations and ultimately affect the value of information provided by the monitoring system.

Since outcome costs listed in the decision tree occur both immediately and in future years, we use a common $30 \mathrm{yr}$ time horizon (equivalent to the life of the monitoring system) and an interest rate of $5 \%$ to bring all future costs to their present value. We also assume that aquifer nitrate concentrations are temporally static over the $30 \mathrm{yr}$ analysis period and people face the same health risk each year. Below we present our methods to estimate the various outcome costs and outcome probabilities listed in the decision tree. Then we describe how we use the outcome costs and probabilities to compute an expected cost for each alternative and the value of information for the groundwater quality monitoring system. The decision tree model and the outcome costs were implemented using Excel spreadsheets.

\subsection{Outcome costs}

As shown in the decision tree (Fig. 3), there are costs associated with the outcomes resulting from each alternative. These outcome costs include:

1. Methemoglobinemia treatment. When aquifer water is contaminated with nitrate and an individual contracts methemoglobinemia, the most common 


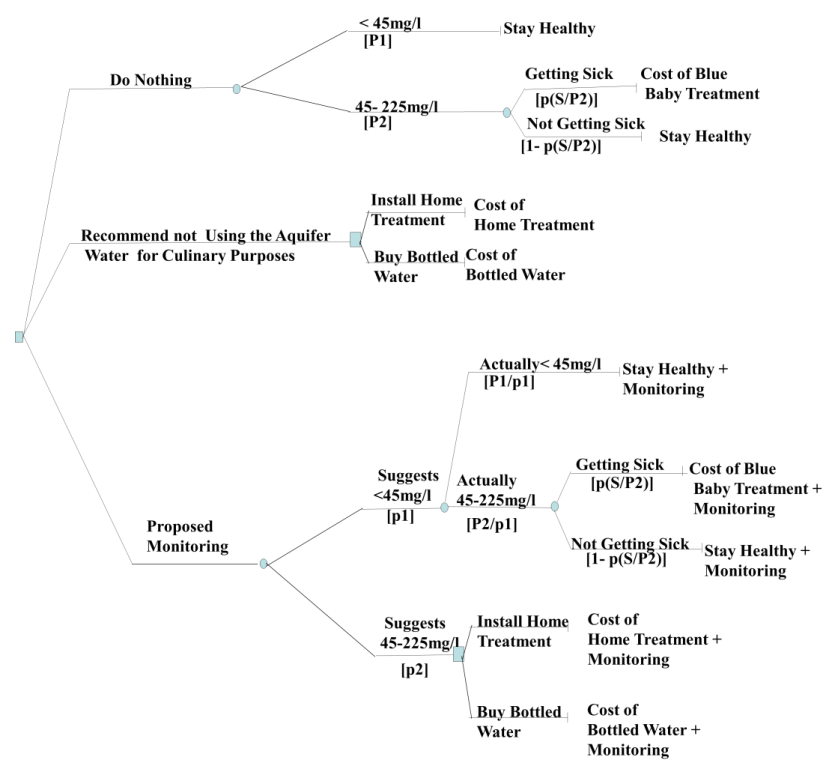

Fig. 3. Decision tree model for the scenario where people fully abide by DM recommendations.

treatment is methylene blue (Majumdar, 2003). The estimated cost of methylene blue treatment for an infant is $\$ 150$ (http://www.revolutionhealth.com/ drugs-treatments/methylene-blue). Additionally, we assume that both parents work, so when an infant gets sick, at least one parent will stay home for 6 work days to care for the infant, as is common in the West Bank. West Bank wages are typically $\$ 50 /$ day. Thus, there is an additional cost of $\$ 300$ in lost salary associated with the outcome of getting sick.

To estimate community-wide costs, we scale the individual costs per family by the number of households served by the pumping well and the $30 \%$ fraction of households that use formula rather than breast milk (Ammar et al., 2008). Absent detailed data on the water distribution system in the study area, we assume that the number of households served by a pumping well is proportional to the pumping rate from the well (Khader, 2012). Additionally, the population in the study area is growing by $3 \%$ per year, so the number of people affected and costs in future years also increase.

2. Switch to alternative sources. In this option people use alternate water sources to make infant formula rather than polluted groundwater. One alternative water source is bottled water, which costs about $\$ 0.6 /$ infant/day or \$220/infant/year. Other alternatives include home distillation, reverse osmosis (RO), or ion exchange units (Jennings and Sneed, 1996). These units are much more expensive than bottled water, and our analysis assumes households will choose the cheaper bottled water option. We use the same methods as for

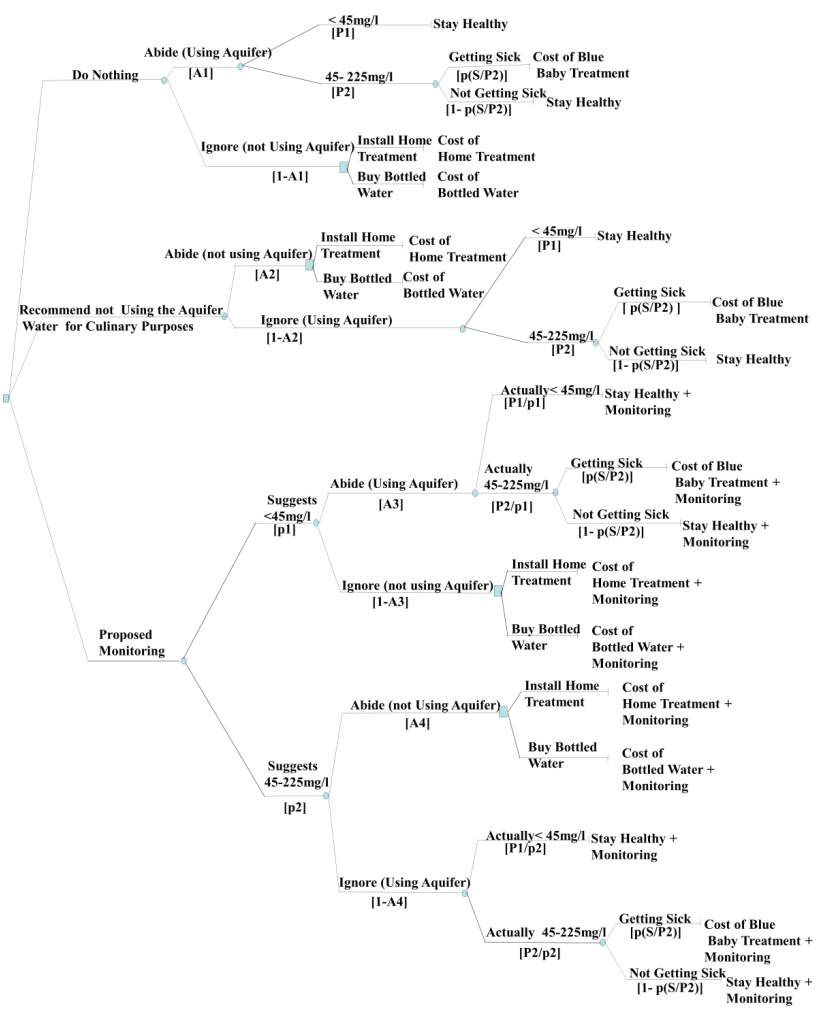

Fig. 4. Decision tree model for the scenario where some people abide by and others ignore DM recommendations.

methemoglobinemia treatment to scale the household cost for bottled water to a community cost based on the estimated number of infants in each household.

3. Monitoring system. The costs to install and operate the 49 wells comprising the monitoring system include three components (CDLE, 2001):

- Drilling cost $(\$ 53.89 / \mathrm{m}$ for a well $<15 \mathrm{~m}$ deep or $\$ 60.45 / \mathrm{m}$ for a well $>15 \mathrm{~m}$ deep),

- Finishing cost $(\$ 49.72 / \mathrm{m})$, and

- Nitrate sampling cost (\$12/well/year), considering only one sample per year for simplicity.

The depth to groundwater at each well is estimated using the groundwater flow model developed in Khader (2012). The total present value cost to install and operate the monitoring system are US\$0.6 million, which includes drilling, finishing, and sampling costs.

There are also additional costs associated with further decisions and outcomes taken in response to the monitoring results. For example, if monitoring suggests the water in an aquifer model cell is not contaminated (nitrate concentration $<45 \mathrm{mg} \mathrm{L}^{-1}$ ), DMs will recommend people to continue to use that water. But the monitoring system is imperfect, and there are still possibilities that the actual nitrate concentration will be above $45 \mathrm{mg} \mathrm{L}^{-1}$ and some people will get 
sick. In this progression of events, these people will require methemoglobinemia treatment at costs described in cost item \#1 above. Similarly, if monitoring suggests the water in an aquifer model cell supplying a pump is contaminated (nitrate concentration $>45 \mathrm{mg} \mathrm{L}^{-1}$ ), DMs will recommend people who use that water to switch to an alternative source. In this case, these people will incur the costs described in cost item \#2 above. Together, the expected cost of the monitoring system includes the present value costs of installing and operating the system plus the present value expected costs of recourse actions and outcomes that occur in response to the monitoring results.

\subsection{Probability estimation}

Probabilities quantify the likelihood of uncertain outcomes such as groundwater quality and public response to DM recommendations. We use probabilities to weigh outcome costs and determine the expected cost for the set of outcomes associated with an alternative. Below we describe the methods used to estimate the probabilities associated with uncertain groundwater quality and public responses.

\subsubsection{Groundwater quality}

Here, we use prior Monte Carlo simulation and RVM model results derived from uncertainties in climate, aquifer properties, and expected nitrate concentrations (Khader, 2012) to estimate the outcome probabilities listed in the decision tree (Figs. 3 and 4). We define each probability and present the method to estimate it.

- $[\mathrm{P} 1]$ is the probability that the actual nitrate concentration in an aquifer model cell is less than $45 \mathrm{mg} \mathrm{L}^{-1}$. We estimate this probability by dividing the number of $\mathrm{MC}$ simulations where concentration in the aquifer model cell was less than $45 \mathrm{mg} \mathrm{L}^{-1}$ by the total number of $\mathrm{MC}$ simulations (10000 for the current study).

- $[\mathrm{P} 2]$ is the probability that the actual nitrate concentration in an aquifer model cell is in the range 45$225 \mathrm{mg} \mathrm{L}^{-1}$. We also estimate this probability from the MC simulations.

- [P3] is the probability that the actual nitrate concentration in an aquifer model cell is greater than $225 \mathrm{mg} \mathrm{L}^{-1}$. $\mathrm{MC}$ results show that nitrate concentration did not exceed $225 \mathrm{mg} \mathrm{L}^{-1}$ in any aquifer model cell in any MC simulations. Thus, P3 is zero and we do not consider this outcome in the decision tree.

- $[\mathrm{S} / \mathrm{P} 1]$ is the probability that an infant will get sick with methemoglobinemia given the nitrate concentration in an aquifer model cell is less than $45 \mathrm{mg} \mathrm{L}^{-1}$. This probability is zero (Walton, 1951).

- $[\mathrm{S} / \mathrm{P} 2]$ is the probability that an infant will get sick with methemoglobinemia given the nitrate concentration is in the range $45-225 \mathrm{mg} \mathrm{L}^{-1}$. This probability is $57 \%$ (Walton, 1951).

- [p1] is the probability that the monitoring network will suggest nitrate concentration in an aquifer model cell is less than $45 \mathrm{mg} \mathrm{L}^{-1}$. We estimate this probability from the RVM model (Khader, 2012) by dividing the number of RVM runs where concentration in the aquifer model cell was less than $45 \mathrm{mg} \mathrm{L}^{-1}$ by the total number of runs (100 in this study).

- [p2] is the probability that the monitoring network will suggest nitrate concentration in an aquifer model cell will be in the range $45-225 \mathrm{mg} \mathrm{L}^{-1}$. This probability is also estimated from the RVM model like for [p1].

- $[\mathrm{P} 1 / \mathrm{p} 1]$ is a posterior probability and is the probability that the actual nitrate concentration in an aquifer model cell will be less than $45 \mathrm{mg} \mathrm{L}^{-1}$ when the monitoring network suggests the aquifer concentration is less than $45 \mathrm{mg} \mathrm{L}^{-1}$. In this circumstance, the monitoring system predicts the correct outcome, and we can use Bayes Theorem to calculate this posterior probability from the prior probability [p1/P1] and probabilities [P1] and [p1] that we already know:

$[\mathrm{P} 1 / \mathrm{p} 1]=\frac{[\mathrm{P} 1][\mathrm{p} 1 / \mathrm{P} 1]}{[\mathrm{p} 1]}$.

Here, the prior probability $[\mathrm{p} 1 / \mathrm{P} 1]$ is estimated by jointly considering the MC simulation and RVM results together and estimating the probability that the monitoring network will suggest the nitrate concentration in an aquifer model cell is less than $45 \mathrm{mg} \mathrm{L}^{-1}$ (RVM results) when the actual nitrate concentration is less than $45 \mathrm{mg} \mathrm{L}^{-1}$ (MC simulations). In this case [p1/P1] is estimated by dividing (i) the number of runs where concentrations in the RVM and MC simulations are both less than $45 \mathrm{mg} \mathrm{L}^{-1}$ by (ii) the total number of runs.

- $[\mathrm{P} 2 / \mathrm{p} 1]$ is the probability that the actual concentration in an aquifer model cell will be in the range 45 $225 \mathrm{mg} \mathrm{L}^{-1}$ when the monitoring network suggests the concentration is less than $45 \mathrm{mg} \mathrm{L}^{-1}$. This case is the complement to $[\mathrm{P} 1 / \mathrm{p} 1]$ and also represents a Type II error: the monitoring system suggests the aquifer water is safe when in fact the water actually poses a risk. Together, the probabilities for the correct outcome ([P1/p1]) and Type II error ([P2/p1]) sum to 1 and comprise all possible outcomes for the situation when the monitoring system suggests nitrate concentration in an aquifer model cell will be less than $45 \mathrm{mg} \mathrm{L}^{-1}$. Thus, we use the law of probabilities to estimate $[\mathrm{P} 2 / \mathrm{p} 1]$ as

$[\mathrm{P} 2 / \mathrm{p} 1]=1-[\mathrm{P} 1 / \mathrm{p} 1]$.

- We use similar methods to estimate [P2/p2] and [P1/p2] as the probabilities that the actual nitrate concentration 
in an aquifer model cell will be in the ranges of, respectively, $45-225$ or $0-45 \mathrm{mg} \mathrm{L}^{-1}$ when the monitoring network suggests the concentration will be in the range $45-225 \mathrm{mg} \mathrm{L}^{-1}$. The probability [P2/p2] also represents a true outcome while [P1/p2] represents a Type I error: the monitoring system suggests the water poses a risk when the water is actually safe.

The above probability estimates are for an individual aquifer model cell. Since the aquifer is heterogeneous, the probability values may also differ by aquifer model cell. In the analysis of alternatives, we use probabilities associated with aquifer model cells that have a withdrawal well and supply people with water.

\subsubsection{Public response}

People's responses to a DM's recommendation are an important factor that determines the structure of the decision tree and likelihood of outcomes, as shown in Fig. 4. To estimate the likelihood that people will abide by DM recommendations, we invited two hundred fifty people living in the area of the Eocene Aquifer to participate in a survey that asked them their perceptions of the current water quality and quantity situation and how they would respond in four hypothetical scenarios where DMs recommend they use/not use aquifer water. The study was approved by the institutional review board at Utah State University, and surveys were administered directly to participants in summer 2011 at service centers throughout the study area where they also pay their water bills. One hundred and ninety-six people living in 26 communities responded. Khader (2012) provides a full description of the survey method and results; here, we focus on the portion of the survey that probes how participants may respond to manager recommendations to use or not use water from the Eocene Aquifer. In the first two hypothetical scenarios, the government simply declared the groundwater is either (i) safe or (ii) not safe to drink. In the third and fourth scenarios, the government monitored and tested the aquifer water then declared the water either (iii) safe or (iv) not safe (Khader, 2012).

Statistical analysis of the responses to the four questions associated with these four scenarios provides estimates of the abidance probabilities A1-A4 (Table 1). Absent monitoring, less than $30 \%$ of participants would abide by recommendations to use the aquifer. However, $96 \%$ of participants would abide by a DM's recommendation if the recommendation is to not use the aquifer. With monitoring in place, more people will abide by the recommendations to use or not to use the aquifer (62\% and $97 \%$ ). Across all the scenarios, people are more likely to abide by a DM's recommendation when the recommendation is to not use the aquifer. Together, the survey responses suggest which types of messages people will follow and characterize the probabilities people will abide by DM recommendations.
Table 1. Probabilities that participants will abide by DM recommendations.

\begin{tabular}{llllrl}
\hline & & \multicolumn{4}{c}{ Probability of abidance } \\
\cline { 3 - 6 } Choice & Recommendation & Label & $\begin{array}{c}\text { Mean } \\
\text { value }\end{array}$ & $\begin{array}{c}\text { Standard } \\
\text { deviation }\end{array}$ & 95\% C.I \\
\hline \multirow{2}{*}{$\begin{array}{l}\text { Without } \\
\text { monitoring }\end{array}$} & Use the aquifer & [A1] & 0.294 & 0.457 & $0.230-0.358$ \\
\cline { 2 - 6 } & Use other sources & [A2] & 0.959 & 0.199 & $0.931-0.987$ \\
\hline \multirow{2}{*}{$\begin{array}{l}\text { With } \\
\text { monitoring }\end{array}$} & Use the aquifer & [A3] & 0.624 & 0.486 & $0.556-0.692$ \\
\cline { 2 - 6 } & Use other sources & [A4] & 0.969 & 0.174 & $0.945-0.993$ \\
\hline
\end{tabular}

\subsection{Expected costs of alternatives and value of information}

We convert all outcome costs to their present values then calculate the expected cost of an alternative as a weighted average of all outcome costs associated with the alternative. We use the outcome probabilities (p1, p2, P1, P2, A1, A2, A3, and A4 in Figs. 3 and 4) as the weights. In the Eocene Aquifer study, present-value expected costs incurred by DMs and the public serve as an adequate proxy for expected value since these costs are the principal factors affecting the expected value of each alternative. A probabilityweighted expected-cost metric is risk-neutral and is appropriate for the case when the magnitudes of outcome costs are small, there are similar types of outcomes across the alternatives, and the DM does not have strong preferences among outcomes with large and small magnitudes.

We then use the present-value expected costs to estimate the value of information of the monitoring network. This value is the difference between the expected costs of implementing the monitoring network and the lowest-cost, uninformed alternative.

\section{Results and discussion}

The present-value expected costs of the options to do nothing (continue to use the aquifer), switch to alternative sources, and install and use the monitoring system range between $\$ 6$ and 7 million (Fig. 5). The two uninformed options (do nothing and switch to alternative sources) have nearly equivalent expected costs; the expected cost to switch to alternative sources is slightly smaller, which identifies the use alternative sources option as the preferred response to potential nitrate contamination in the Eocene Aquifer. The expected cost for the monitoring system is larger than either of the uninformed options, which suggests that information provided by the monitoring system does not have value under the modeled assumptions. The monitoring system does not have value because implementing an uninformed option gives a lower expected cost.

When the abidance ratio was relaxed to the values of probabilities A1-A4 estimated from the survey results (i.e., some 


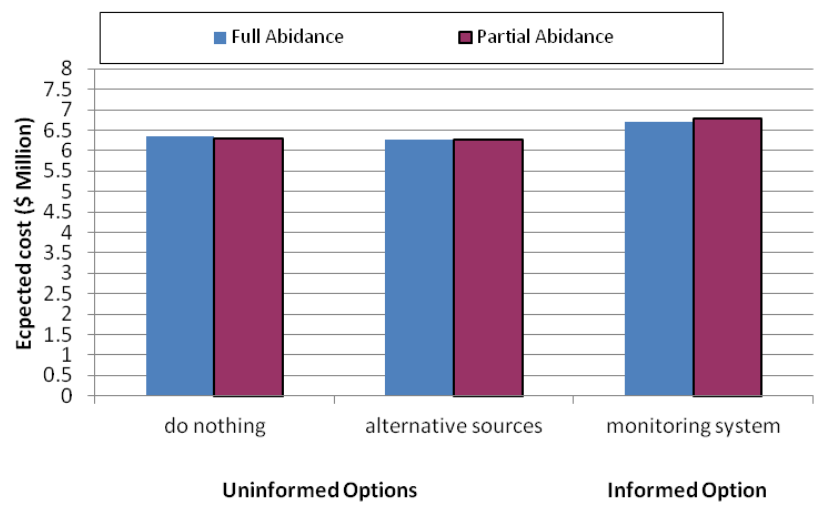

Fig. 5. Present-value expected costs of alternatives.

people will ignore DM recommendations), the expected cost of the monitoring system slightly increases (purple bars in Fig. 5). Expected costs only increase slightly due to the results of the survey which showed that the abidance rate is high in 3 out of 4 scenarios (the values of A2, A3, and A4 are $0.96,0.62,0.97$, respectively, as shown in Table 1). Importantly, this result shows how public awareness, acceptance, and compliance with health safety messages affect the value of information provided by a monitoring network. The result suggests that public outreach to local communities through town hall meetings, media advertising, education campaigns in schools, and the like should be part of monitoring programs since more people abiding with DM recommendations reduces overall costs and increases the value of information provided by monitoring.

We estimate the upper bound on WTP for the monitoring system as the difference in expected costs associated with (i) recourse actions taken after implementing the monitoring system, and (ii) the best uninformed option to not use the aquifer. Figure 6 shows that this WTP, which is measured ex ante, is below the expected costs to install and operate the monitoring system. This result shows that the proposed monitoring system does not have value.

However, this ex ante approach to estimate WTP allows us to further study monitoring systems with unknown installation and operation costs such as a hypothetically perfect monitoring system that always estimates nitrate concentrations in their actual ranges. In the decision tree model, we represent a perfect monitoring system by changing the values of the posterior probabilities [P1/p1] and [P2/p2] to 1 and the probabilities associated with Type I and II errors ([P1/p2] and [P2/p1]) to 0. Model results for the perfect monitoring system show that WTP increases (Fig. 6). Should people fully abide by DM recommendations, WTP for perfect monitoring exceeds the present value costs to install and operate the proposed (imperfect) monitoring system. For the case of partial abidance with DM recommendations, WTP for perfect monitoring is below the costs of the proposed system. When WTP for a perfect system is below the actual system cost,

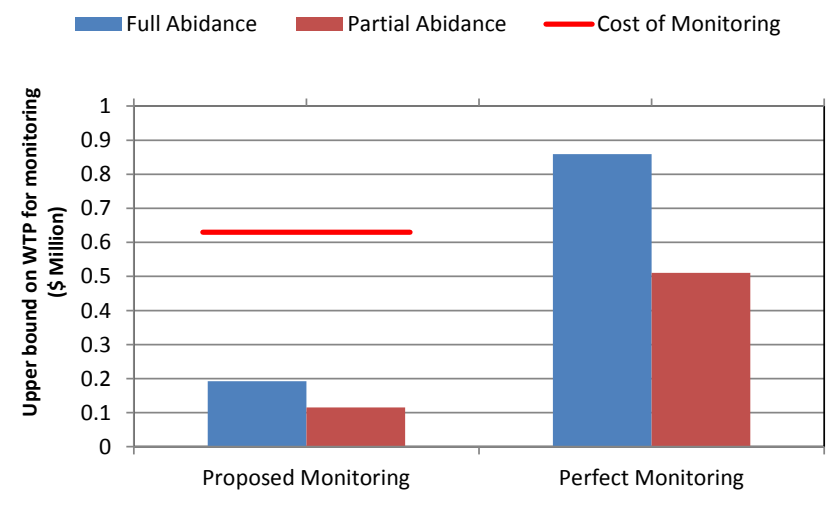

Fig. 6. Upper bounds on willingness-to-pay for monitoring systems.

analysts often suggest that DMs should not invest in monitoring (Yokota and Thompson, 2004b). However, lowering the monitoring system capital and operating costs (red line in Fig. 6) to $\$ 0.2$ million (in the case of full abidance) or $\$ 0.1$ million (with partial abidance) would make the monitoring system investment worthwhile. DMs could lower the monitoring system capital costs by reducing the number of monitoring wells or moving wells to locations where it is less expensive to install them. Alternatively, DMs could improve monitoring system accuracy by including other sources of uncertainty like human activities and on-ground nitrate loading, and considering temporal variations in nitrate concentrations (Khader, 2012). The WTP results show how monitoring system size, design, accuracy, public abidance with DM recommendations, and capital and operating costs together influence the value of information provided by the monitoring system.

Sensitivity analysis further shows how the value of information provided by the monitoring system is affected by financial, demographic, and demographic-hydrogeological factors. For example, when the cost of methylene blue treatment rises above $\$ 300$ per person, the expected cost for the do nothing option surpasses the expected costs for the monitoring system and monitoring becomes preferable to doing nothing (results not shown). Similarly, the monitoring system is preferable to the bottled water option when the bottled water cost rises to $\$ 2.3 /$ baby/day. When the population using the aquifer increases to 1.2 million, the expected costs for both uninformed options surpass the expected cost for the monitoring system, in which case the monitoring system has value. These results show that financial characteristics of the uninformed alternatives, as well as demographics, affect the value of information.

Beyond the demographic factor of the number of people using the aquifer, monitoring system VOI is also influenced by where people are located relative to aquifer hydrogeological characteristics such as nitrate-contaminated areas. To study this effect, we first noted that in the prior results, $86 \%$ of the population is served by wells that draw from locations in the aquifer where the expected nitrate concentration 
is greater than $45 \mathrm{mg} \mathrm{L}^{-1}$ and may pose a health risk. (Similarly, $14 \%$ of the population is served by wells that pose little health risk.) These results stem from the prior assumption that the number of households served by a pumping well is proportional to the well pumping rate. Second, we varied the percent of the population served by wells that pose a health risk from 0 to $100 \%$ and calculated the expected costs for each alternative with partial abidance. These scenarios can be interpreted to represent either demographic (i) proximity to wells where nitrate concentration is greater than $45 \mathrm{mg} \mathrm{L}^{-1}$, or (ii) migration towards or away from such wells. As anticipated, results show that do nothing is the low-cost, clearly preferred option when $0 \%$ of the population is at risk (Fig. 7, far right). Similarly, switch to alternative sources is the lowcost, preferred option when $100 \%$ of the population is served by wells where nitrate poses a health risk (Fig. 7, far left). Interestingly, expected costs increase for all options as more of the population is served by wells that pose a risk. However, expected costs increase fastest for the do nothing option and slowest for the alternative sources option, so alternative sources become preferable when $86 \%$ or more of the population is served by wells that pose a health risk. Across the scenarios, the expected costs for the monitoring system are always greater than costs for one of the uninformed options. However, the gap narrows between the expected costs of the monitoring system and the least-cost uninformed option as more of the population is served by wells that pose a health risk. This gap, representing the value of information of the monitoring system, is less than the $\$ 0.6$ million capital and operating costs of the monitoring system in scenarios where more than $86 \%$ of the population is served by wells that pose a health risk, which suggests, as discussed previously, that there is value to a monitoring system with lower capital and operating costs. This value is also affirmed by noting that the DM does not presently know what percentage of the population faces a health risk. Thus, should s/he recommend do nothing or switch to alternative sources? To answer this question, the DM will need to monitor, and the $\$ 0.3$ million gap between monitoring and the expected costs of the do nothing and switch to alternative sources options when $100 \%$ of the population is at risk represents an upper bound on a DM's WTP to monitor. The DM's actual WTP may be less and will depend on his/her prior information regarding aquifer contamination and the likelihood s/he associates with the outcome that the entire population will be at risk. These scenarios show that monitoring system VOI is also influenced by where people are located relative to aquifer hydrogeological characteristics such as nitrate-contaminated areas.

Together, the decision tree model, VOI results, and sensitivity analyses show that the proposed monitoring system for the Eocene Aquifer does not have value and that uninformed options like switch to alternative sources are lower-cost. However, the VOI provided by the monitoring system is affected by important public acceptance, system design, financial, demographic, and demographic-hydrogeological factors

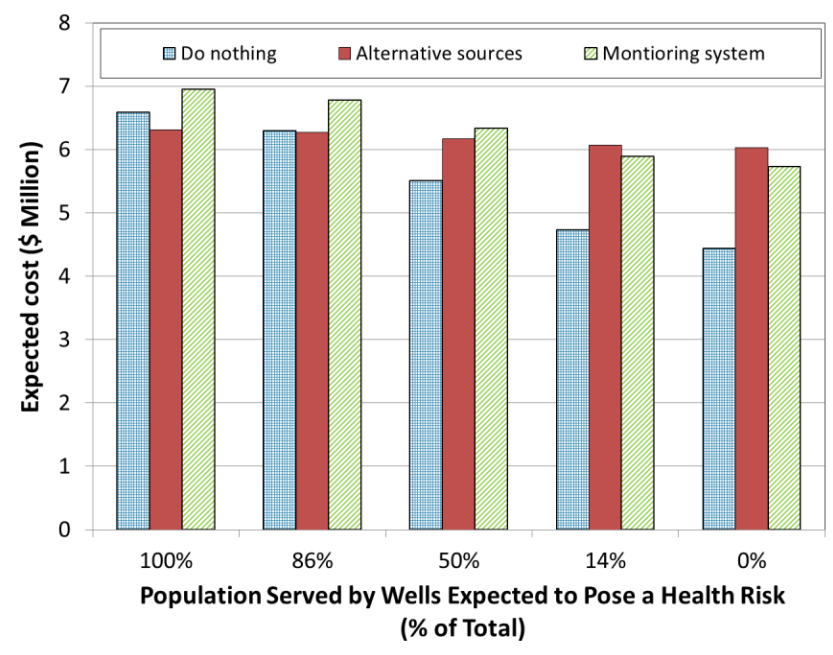

Fig. 7. Expected costs for alternatives with partial abidance under population redistribution scenarios where more/less people use the nitrate-contaminated aquifer water.

such as whether people abide by DM recommendations, accuracy of the monitoring system, installation and operation costs, costs of uninformed alternatives, the number of people served by the aquifer, and where people live in relation to areas with nitrate concentrations that pose health risks. These results indicate that there is WTP for a monitoring system, but the system installation and operating costs for the proposed system will need to decrease by half to $\$ 0.3$ million or less for the system to have value. Besides using fewer monitoring wells (with potentially some loss in concentration prediction ability), DMs could alternatively lower the monitoring system cost by including costs to drill and finish wells as additional criteria in the RVM design and selection of monitoring well locations. This latter approach identifies the potential benefit to embed value of information methods directly in the monitoring network design process.

\section{Conclusions}

This paper presents a decision tree method to estimate the value of information provided by a groundwater quality monitoring network located in an aquifer whose water poses a spatially heterogeneous and uncertain health risk. We use the decision tree to describe the structure of the decision alternatives facing the DM, as well as likelihoods and expected outcomes of these alternatives. The alternatives include (i) do nothing (continue to use the aquifer and ignore the health risk of nitrate-contaminated water), (ii) switch to alternative water sources, or (iii) implement a previously designed groundwater quality monitoring network that takes into account uncertainties in aquifer properties, contaminant transport processes, and climate. We estimate the value of information provided by the monitoring network as the difference 
between the present-value expected costs of the monitoring network and the lowest-cost uninformed alternative.

We illustrated the method for the Eocene Aquifer, West Bank, Palestine, where methemoglobinemia is the main health risk associated with nitrate contamination. We estimated the expected costs of each alternative as the weighted sum of the costs and probabilities (likelihoods) associated with the potential outcomes resulting from the alternative. Potential outcomes included contaminant concentrations in individual aquifer model cells, concentrations reported by the monitoring system, whether people abide by manager recommendations to use/not use aquifer water, and whether people get sick from drinking contaminated water. The likelihoods of these outcomes were derived from Monte Carlo simulations of uncertain aquifer properties, RVM results, surveys of people's likely responses to official pronouncements regarding aquifer water quality, and prior health studies. Outcome costs included healthcare for methemoglobinemia, purchasing bottled water, and installing and maintaining the groundwater monitoring system.

Decision tree results show that the expected cost of establishing the proposed monitoring network exceeds the expected costs of the uninformed alternatives and there is no value in the information the system provides. Eocene Aquifer managers should instead recommend that families use alternative sources like bottled water to make baby formula.

The value of information provided by the monitoring system is further diminished when only part of the affected population abides by DM recommendations to use/not use the aquifer. However, should bottled water costs increase to $\$ 2.3 /$ baby/day, methemoglobinemia costs rise to $\$ 300 /$ person, or the population served by the aquifer increase above 1.2 million persons, DMs should prefer the monitoring system to switching to alternative sources or ignoring the health risk. A monitoring system with lower installation and operating costs or that more accurately reports actual aquifer concentrations would likewise have value. Designers could lower system costs by either (i) using fewer monitoring wells, or (ii) including the costs to drill and finish wells as additional criteria in the RVM to select monitoring well locations.

The VOI analysis offers Eocene Aquifer managers specific recommendations to respond to the nitrate contamination in the West Bank, Palestine. The analysis also shows how the value of information provided by a monitoring system is affected by important system design, public acceptance, financial, demographic, and demographic-hydrogeological factors like monitoring system accuracy, installation and operation costs, whether people abide by DM recommendations, costs of uninformed alternatives, the number of people served by the aquifer, and where people live in relation to areas with nitrate concentrations that pose health risks. Monitoring groundwater quality in the Eocene Aquifer has value, but most likely using a modified version of the proposed monitoring system.
Acknowledgements. This research was funded by the Utah Water Research Laboratory in Logan, UT. The authors thank Arthur Caplan from the Department of Applied Economics at Utah State University for comments on earlier drafts.

Edited by: D. Solomatine

\section{References}

Alberini, A., Hunt, A., and Markandya, A.: Willingness to Pay to Reduce Mortality Risks: Evidence from a Three-Country Contingent Valuation Study, Env. Resource Econ., 33, 251-264, 2006.

Alfonso, L. and Price, R.: Coupling hydrodynamic models and value of information for designing stage monitoring networks, Water Resour. Res., 48, W08530, doi:10.1029/2012WR012040, 2012.

Almasri, M. N. and Kaluarachchi, J. J.: Multi-criteria decision analysis for the optimal management of nitrate contamination of aquifers, J. Environ. Manage., 74, 365-381, 2005.

Ammar, K., Khalil, A., McKee, M., and Kaluarachchi, J.: Bayesian deduction for redundancy detection in groundwater quality monitoring networks, Water Resour. Res., 44, W08412, doi:10.1029/2006WR005616, 2008.

Arrow, K. J. and Lind, R. C.: Uncertainty and the Evaluation of Public Investment Decisions, Am. Econ. Rev., 60, 364-378, 1970.

Atkins, J. P., Burdon, D., and Allen, J. H.: An application of contingent valuation and decision tree analysis to water quality improvements, Mar. Pollut. Bull., 55, 591-602, 2007.

Bouma, J. A., van der Woerd, H. J., and Kuik, O. J.: Assessing the value of information for water quality management in the North Sea, J. Environ. Manage., 90, 1280-1288, 2009.

Chia-Yu Lin, A., Andrew, G., Phillip, N. P., and David, H. K.: Analysis of Local Decisions Using Hierarchical Modeling, Applied to Home Radon Measurement and Remediation, Stat. Sci., 14, 305337, 1999.

Colorado Department of Labor and Employment (CDLE): Maximum reasonable costs - drilling, 2001.

Dakins, M. E.: The Value of the Value of Information, Human and Ecological Risk Assessment, 5, 281-289, 1999.

Dakins, M. E., Toll, J. E., and Small, M. J.: Risk-based environmental remediation: Decision framework and role of uncertainty, Environ. Toxicol. Chem., 13, 1907-1915, 1994.

Dakins, M. E., Toll, J. E., Small, M. J., and Brand, K. P.: RiskBased Environmental Remediation: Bayesian Monte Carlo Analysis and the Expected Value of Sample Information, Risk Anal., 16, 67-79, 1996.

Delquié, P.: Valuing information and options: an experimental study, J. Behav. Decis. Making, 21, 91-109, 2008.

DeShazo, J. R. and Cameron, T. A.: The Effect of Health Status on Willingness to Pay for Morbidity and Mortality Risk Reductions, On-Line Working Paper Series, California Center for Population Research, UC Los Angeles, 2005.

Dickie, M. and Gerking, S.: Willingness to Pay for Reduced Morbidity, Paper presented at the workshop, "Economic Valuation of Health for Environmental Policy: Assessing Alternative Approaches", at the University of Central Florida, Orlando, Fla., 18-19 March, 2002.

Engle-Warnick, J., Héroux, J., and Montmarquette, C.: Willingness to Pay to Reduce Future Risk, CIRANO Scientific Series 2009s- 
27, Montreal, Canada, 2009.

Friedman, D. and Sunder, S.: Experimental Methods: A Primer for Economics, Cambridge University Press, New York, NY, 1994.

Jennings, G. D. and Sneed, R. E.: Nitrate in Drinking Water, North Carolina Co. Ext., AG, 473-474, 1996.

Khader, A.: Value of Information in Design of Groundwater Quality Monitoring Network Under Uncertainty, PhD dissertation. Utah State University, Logan, UT, 2012.

Latvala, T. and Jukka, K.: Consumers' Willingness to Pay for Additional Information on Food Quality and Safety, Conference Paper, 84th EAAE Seminar, 2004.

LaValle, I. H.: On Cash Equivalents and Information Evaluation in Decisions Under Uncertainty: Part I: Basic Theory, J. Am. Stat. Ass., 63, 252-276, 1968.

Lorna, F.: Drinking-water nitrate, methemoglobinemia, and global burden of disease: A discussion, US Department of Health and Human Services, Research Triangle Park, NC, ETATS-UNIS, 2004.

Lund, J. R.: Probabilistic Design and Optimization Class Notes, Class Notes, ECI 249, Winter, 2009.

Majumdar, D.: The Blue Baby Syndrome, Resonance, 8, 20-30, 2003.

Molin, E. J. E. and Timmermans, H. J. P.: Traveler expectations and willingness-to-pay for Web-enabled public transport information services, Transportation Research Part C: Emerging Technologies, 14, 57-67, 2006.

Najem, A.: Modeling Nitrate Contamination of the Eocene Aquifer, Palestine, M.S. thesis, An-Najah National University, Nablus, 2008.

Palestinean Central Bureau of Statistics (PCBS): Palestine in Figures 2007, 2008.
Palestinean Central Bureau of Statistics (PCBS): Population, housing and establishment census 2007, main indicators by locality type, 2009.

Pattanayak, S. K., Smith, V. K., and Van Houtven, G.: Valuing environmental health risks: from preference calibration to estimation, Working Paper 0304, RTI International, 2003.

Perloff, J. M.: Microeconomics: theory \& applications with calculus, Pearson Addison Wesley, 2008.

Rajagopal, R.: The Effect of Sampling Frequency on Ground Water Quality Characterization, Ground Water Monitoring \& Remediation, 6, 65-73, 1986.

Repo, A. J.: The value of information: Approaches in economics, accounting, and management science, J. Am. Soc. Inform. Sci., 40, 68-85, 1989.

Roe, T. and Antonovitz, F.: A producer's willingness to pay for information under price uncertainty: Theory and application, Southern Econ. J., 52, 382-391, 1985.

Sakalaki, M. and Kazi, S.: How much is information worth? Willingness to pay for expert and non-expert informational goods compared to material goods in lay economic thinking, J. Inf. Sci., 33, 315-325, doi:10.1177/0165551506070709, 2007.

Walton, G.: Survey of literature relating to infant methemoglobinemia due to nitrate-contaminated water, Am. J. Public Health, 41, 986-996, 1951.

Yokota, F. and Thompson, K. M.: Value of Information Analysis in Environmental Health Risk Management Decisions: Past, Present, and Future, Risk Anal., 24, 635-650, 2004a.

Yokota, F. and Thompson, K. M.: Value of Information Literature Analysis: A Review of Applications in Health Risk Management, Med. Decis. Making, 24, 287-298, 2004b. 